\title{
DIJITAL ÇAĞDA SAVAŞ: DRON ÖRNEĞi
}

\section{Ertan KARDEŞ*}

\begin{abstract}
Özet
Günümüzde savaşlar biçim, tarz ve yapısal anlamda dönüşmektedirler. Klasik savaşlardan, şiddet hallerine doğru bir geçiş gerçekleşmektedir. Savaşın normatif düzeyleri yerini, belirsiz ve tanımsız durumlara bırakmaktadır. Bu anlamda savaşa dair yeni figürler çoğalmaktadır. Muharip ve simetrik güçlerin yaptığı savaşlardan dronların, bilkuvve teröristlerin ve şirketlerin yaptığı şiddet sarmalına doğru bir geçiş gerçekleşmiştir. Dron, yeni savaşların ya da şiddet hallerinin yeni figürlerinden yalnızca bir tanesidir. Bu makalede diğer figürler yok sayılmadan fenomenolojik bir yöntemle dron incelenmiştir. Dronun iddiası daha "insani" bir öldürme biçimi geliştirmiş olmasıdır. Ancak makalede dron ve robotiğin, savaşlarda yol açtığı düzeltilemez ve geri çevrilemez sorunlar vurgulanmaktadır. Dron, düşmanını insanlıktan men ederek, bir politik topluluğun kendisini "insanlık” adına kısırlaştırma pratiğini anlatmaktadır. Dron her şeyden önce çağın krizinin kanıksanarak sürdürülmesi süreçlerine gönderme yapmaktadır.
\end{abstract}

Anahtar Kelimeler: politik felsefe, savaş, dron, yeni savaşlar, G. Chamayou. 


\title{
THE WAR IN THE DIGITAL ERA: THE EXAMPLE OF THE DRONE
}

\author{
M. Ertan KARDEŞ*
}

\begin{abstract}
Nowadays, wars are being transformed in form, style and structure. There is a transition from classical wars to states of violence. The normative levels of war leave its place to ambiguous and undefined situations. In this sense, new figures about war are multiplying. There has been a shift from wars made by symmetrical and belligerent forces to orgies of violence practiced by drones and virtual terrorists. Drone is only one of the new figures of new wars or states of violence. This article focuses on the figure of the drone with a phenomenological methodology without ignoring the other new figures of war. The claim on the use of the drone is that the drone develops a more "humane" way of killing. However, in this article, it is emphasized that the drone and the robotics in wars give rise to incorrigible and irreversible problems. By excluding his enemy from his humanity, the drone explains the sterilization of his political community in the name of humanity. In that case, the drone is referring to the processes of maintaining the crisis of the age.
\end{abstract}

Keywords: political philosophy, war, new wars, drone, G. Chamayou.

* Associate Professor, İstanbul University, Faculty of Letters 


\section{Giriş}

Savaşın 20. yüzyılda değişen karakteri sorununa odaklanmak gerekmektedir. Savaşın değişen yüzü, barış kavrayışlarımızı da değiştirir. Savaş yapma biçimleri ve içerikleri değişirken, barışa dair "yenilmez" ve "mutlak" imgemizin değişmiyor oluşu hatta ona dair sarsılmaz güvenimiz politik bir düzeye işaret ediyor olamaz. Nasıl ki savaşçıllık (Fr. bellicisme) ve militarizm savaşın kendisi değildir, aynı şekilde barışçıllık da barış değildir. Genellikle savaş̧̧ıllık ve militarizm ideolojisi eleştirisi yapan bir pasifik eleştiri, tüm barış ve savaş diyalektiği meselesini düşünsel olarak kapatmaktadır.

Pasifizasyon fikri modern bir fikirdir: Rousseau (1762) ve Kant'tan (1795) sonra görülmeye başlanır. Ancak Schmitt (1932: 25-33) bizi barış fikrine dair apolitik yaklaşımlar konusunda uyarmaktadır. Uluslararası alanın çoğulluğu ve tahakküm fikrini ihmal ederek, barış fikrini devlet ve birey arasında inşa eden bir kavrayış vardır. Oysa Schmitt şunu hatırlatmaktadır: Barış istendi diye hiçbir zaman barış olmaz (1932: 33). Barış çoğu kez barış fikriyle savaş fenomenine dair bir kavrayış göz ardı edilerek düşünülmektedir.

Barış fikri savaş fenomeninden ayırt edilemez. Bu teorik bir yanılgıdır. 20. yüzyılda bildiğimiz savaş tanımları kökten bir şekilde dönüşüme uğramıştır. Dönüşen savaştan bahsedince kafamızın içinde olduğunu sandığımız "tutarlı ve huzurlu barış" (irenik imge) kavramının imha edildiğine dair bir kavramsal yol aralanmış olur. Savaş ne insanın yıkıcı doğasının dolayımsız sonucudur, ne de devletlerin irrasyonel kararlarının. Savaş zaten kaotik olan bir uluslararası sistemin genel haline içkindir ama bu içkinlik tarih dışı bir biçimin varlığına gönderme yapmaz.

Burada bizim için daha dikkat çekici olan husus, fiili dünyada savaşın klasik karakterinin dönüşüme uğramış olmasıdır. Denilebilir ki, klasik devletler savaşından uzaklaşıldıkça sınırsız şiddet hallerine daha fazla ilerlemekteyiz. Klasik anlamda savaşlar azaldıkça yerlerini şiddet hallerine, iç savaşlara, vekalet savaşlarına ve klasik savaş hukukunun normatif düzeylerinin içinde olmayan yeni düzeylere bırakmaktadır. Muharip ve simetrik güçler savaşından dronlarla bilkuvve terörizmin şiddet orjisine doğru giden süreç nasıl oluştu?

\section{Savaşın Değişen Yüzleri}

Savaşın değişen doğasına ilişkin tarihsel tasnifler ve ayrımlar çeşitlidir. ${ }^{1}$ Bu tas-

\footnotetext{
${ }^{1}$ Bu tasnifler için tarafımızdan yazılan şu makalede (Kardeş, 2016) ayrımlar daha ayrıntılı olarak ele alınmıştır: "Özetlemek gerekirse, Chaliand'nın 'mutlak amacı olan savaşları', Barnavi'nin 'rasyonel savaşları', Kaldor ve Münkler'in 'eski savaşları', Creveld'in 'ideal olarak devlet çağının savaşı' ve Gros'nun 'şiddet hallerine karşı savaş' tanımlarının Hegel'in ve çağını yansıtan savaş kavrayışları olduğunu görürüz. Hiç şüphesiz farklı disiplinlerden gelen ve farklı bağlamlarda tartışmaya açılmış bu metinlerin birbirlerinden oldukça farklı
}

98 | ETKileşim |Yıl1|Sayı2|Ekim 2018 
niflerin çoğu bize devletlerin savaş tekeli olduğu düzenin değişmekte olduğunu anlatmaktadır. Devletlerarası savaşın son bulmasıyla kitlelerin dahil olduğu ve politika ile savaş arasındaki ilişkinin tersine döndüğü tarihsel bir moment belirmiştir. Schmitt (1975) bunun kaynağını Napoléon dönemine kadar götürmektedir. 'İspanyol gerilla'sı ile başlayan 1. ve 2. Dünya Savaşları ile devam eden sürecin sonunda beliren 'partizan'a kadarki süreçte, devlet artık savaşın tekeli olmayı yitirmiştir (Schmitt, 1975: 6). Devletin egemenlik alametlerinden biri olarak savaşın sönümlenmesi, başka bir deyişle savaş hakkının yitirilmesi, savaşın bıraktığı boşluğun kitleler alanına doğru genişleyen bir şiddetle yer değiştirmesine yol açmıştır. Hegel ve Clausewitz'in savaş kavrayışları kitlelerin maruz kaldığı sınırsız bir şiddetten ziyade, devletlerarası bir savaşa işaret etmektedir (Kardeş, 2016: 131-132)

Savaşın politik karakteri onun barış kuruluşu ile olan ilişkisine yaslanmaktadır. Savaşın gerçekliği barışın tesisidir, ancak barışın ilanı savaşı gerektirmektedir. Kozmopolitist düşüncenin en büyük hatası, insanlık fikrini politik aygıtlar dışında tanımlama çabası olmuştur. İnsanlığın barış içinde yaşayabileceğine dair görüş, herhangi bir politik biçimden yoksundur: Barışın politik momentlerden yoksun, özellikle de etik yaşamın (Alm. Sittlichkeit) ötesinde kurulabileceğine dair bir yanılmayı içermektedir. Savaş bir yandan kendi aralarında birer kişilik gibi eylemde bulunan devletler alanına, diğer yandan da devletlerin kendi içlerindeki etik yaşamın kurulmasına gönderme yapmaktadır.

\section{Kaotik Hal içinde Barış}

Çağdaş barış imgesine dair en somut ve barış imgesinin alışıldık biçimleriyle çelişen resmi, Aron (1962: 323) ortaya koymuştur: "Termonükleer çağda barış" terimi bunu anlatmaktadır. Barışa ontolojik bir nötralite atfedilir. Pacem bir "repos", dinlenme halidir. İki savaş arasında dinlenilir. Böylelikle de silahları susturan koşullar, barışın koşulları olmaktadır. Nükleer barış tabiri tam da bu tezadı anlatmaktadır. Dengenin başlıca unsurları "karşılıklılık" ve "simetri"dir. O halde barışın koşulları ile karşılıklılığın ve simetrinin yaygınlaşması arasında bir ilgi vardır. Muhariplerin olmadığı bir saldırı savaş olarak adlandırılamaz. Sınırsız bir güç uygulamasıdır. Artık liberal demokrasiler aralarında klasik savaşlardan vazgeçmiştir. O halde demokrasileri tehdit eden artık terör, vekalet savaşı ve tanımsız şiddet halleri olmaktadır. 1945 sonrası nükleer barışın dünyaya sunduğu manzaralardan bir tanesi budur.

Klasik barış teorisini sürdürmek mümkün değildir. Agamben'in (2015) de

iddiaları mevcuttur; ancak bu metnin odaklanmak istediği husus her şeyden önce günümüzdeki şiddet halleri ve savaş figürlerinin Hegel ve Clausewitz'in anladığından çok farklı olduğudur. O halde tüm bu dönemselleştirmenin gösterilmesinin amacı Clausewitz'in ve Hegel'in evreninde savaşın hangi savaş tarzına tekabül ettiğini göstermektir. Hegel-Clausewitz çağının savaşı savaşın tekeli olarak devletin, karar alabildiği savaştır". 
belirttiği "uzlaşımcı" hukuki teoriler, fiili fenomeni düşünmemektedir. Liberalizm ve ekonomi eksenli hümanist dünya görüşü bize barışçılık ideolojisiyle barış adına hiçbir şey sunmamaktadır. Esas sorun muharip figürlerin ortadan kalkmasıdır. Muharip figürler yerlerini belli belirsiz figürlere bırakmıştır: Sivil, paramiliter, robotik, partizan vb.

O halde yapılması gereken ilk olarak yeni olan şeylerin saptanmasıdır. Bunun fikri olmadan sadece hümanist safsata üretmiş oluruz. Savaşın devletin tekelinden çıkması: Şiddetin özelleştirilmesi ve asimetrinin disimetri lehine işlemesi. Yeni savaşlar eski savaşların mantığını ve tarzlarını bütünüyle ortadan kaldırmamaktadır. Kısmi olarak yok etmektedir. Ancak bu kısmi yok ediş yeni ve eski figürler arasında sınırsız ilginin yeniden kurulmasına izin vermektedir. Böylelikle daha öngörülemez bir alan belirmektedir. Yeni savaşlar eskilerin mantığıyla birlikte, onların mantığına karşı ve kendi mantıklarıyla yeni bir çatışma alanı açmaktadır. Münkler'in deyimiyle, ucuz ve "sıfır-kayıplı" savaşın ağır bir faturası olmaktadır (2010: 17-59): Bu fatura dünyayı dünyasızlaştırdığı gibi şiddeti de artırmaktadır.

Bu durumda, savaş olağan hallere daha fazla gönderme yaparken, barış bir istisna olarak belirmektedir. Barışın kurulması sanki önceden var olan dingin ve bozuşmuş bir hale geri dönüş değil, yepyeni bir kuruluş sürecidir. iç̧inde çatışmasızlık fikrini de içermez. Barış istediğinde, barışın politik olmayan bir karakterde tasarlanması ya da barışın, eninde sonunda içinde bir yenilgi-galibiyet ya da her iki tarafın da simetrik/asimetrik bir tatminsizlik yaşamadığı bir momentin varsayılması, barış kuruluşu için en büyük engeller arasındadır. Barışın olmasının zorunluluğu çoğunlukla savaşın olumsallığına göre daha az talep edilir. Plastik çağın yeni savaş figürleri ise barışın istisnai konumunu bile olumsallıktan çıkarmaya yetecektir.

\section{Dron Figürü}

Dron, Türkçeye ilk aktarıldığı sıralarda "insansız Hava Aracı" olarak adlandırılmıştı. Oysa dron hava, kara (yeraltı, yerüstü) ve deniz aracı olabildiği gibi, "insansız" olmanın - kumanda edilebilirlik sınıfının da ötesinde, insan ve makine ${ }^{2}$

\footnotetext{
${ }^{1}$ Alexandre Koyré'nin "Filozoflar ve Makine" (1981) adlı metni, felsefe, filozof, teknik ve makine arasındaki "ilgi"nin kısa bir tarihini sunmaya çalışmaktadır. Koyré bu metninde en temelde felsefecinin teknik olana ilişkin tavrının felsefî nedenlerinin nasıl bulanabileceğine dair "soru”lar sormaya çalışmaktadır (1981: 305-339). Birinci bölüm olan "Makinizmin değerlendirmesi" nin hemen başında Koyré, Schuhl'dan hareketle, filozofun makineye ilişkin tavrına dair üç temel dönemselleştirme yapar: Antik çağ teknikle ilgili olarak ümitsizce boş vermişlik çağı, modern çağ coşkulu bir ümitlenme çağı ve çağdaş dönem ise ümidi kalmamış bir bırakma olarak değerlendirilir (Koyré, 1981: 305). Çağdaş dönemde makinenin, insanlığın çektiği sıkıntı ve eziyeti sanıldığı gibi hafifletmediği görülmüştür, yani insanlığın makineye yüklediği ümitler boşa gitmiştir. Koyré'nin deyimiyle, makine insanlığın altın çağı olacakken demir çağı olmuştur (1981: 308). Aristoteles'in bahsettiği
}

$100 \mid$ ETKileşim | Yıl 1 $\mid$ Sayı2| Ekim 2018 
arasındaki ilişkinin yeni bir evresine tekabül etmektedir. Askeri tarihte en uzun menzili 500-600 metre olan oktan, soğuk savaşta kilometrelerce menzili olan füzelere geçiş, yerküredeki askeri ve politik bölüşümler açısından yeni bir çağı anlatmaktaydı. Benjamin'in “Teknik Yeniden Üretilebilirlik Çağında Sanat Yapıtı" (1991: 709-739) metninde ortaya koymaya çalıştığı bu dönüşüm, dronların daha etkin kullanımıyla yeni bir hal almıştır. Savaşta dronlar ne anlama gelmektedir? Teknik yeniden-üretim çağında dronlar, yakınlık-uzaklık, karşılıklı ilişki ve savaş kavrayışı açısından hangi dönüşümleri ortaya koymaktadır?

Bu konuda oldukça fazla metin olduğunu söylemek mümkündür. Ancak Grégoire Chamayou'nun Dron Teorisi (2013) adlı kitabı oldukça etkileyici bir incelemedir. Chamayou'nun "dron" üzerine çıkarımlarının bu sorulara yanıt vermek açısından yetkin olduğunu söylemek mümkündür. Chamayou bu kitabında dronu betimsel, etik, hukuki, politik ve teknolojik açıdan incelemektedir. Dron figürü etrafındaki temsillerin ifşasını sunmaktadır.

Chamayou'nun (2013) dikkati çektiği en önemli husus, dronun ortaya koyduğu savaş pratiği etrafında, savaşa ilişkin tüm kavrayışları parçaladığıdır. Muhabere etmeyen savaşçı, yenilmeyen ordu, sıfır kayıplı savaş, risksiz savaş vb. Dron, fiilen savaşa dair tüm bilinenleri yeniden tanımlama ihtiyacı doğurmaktadır. Sözde daha "insani" bir icat olarak dron, savaşı daha "insanileştirerek" ve de "insanca" öldürerek, insanca mücadele ve üretim biçimlerini yerinden etmektedir.

Sanayi devrinin ütopyalarından biri de, insanların savaşını makinelerin savaşıyla ikame etmek olabilir. Ancak Chamayou bize iyimser ya da kötümser bir tavrın ötesine geçerek, fiilen bu ikamenin gerçekleştiğini ve artık söz konusu olanın uzaktan kumanda edilen savaş makineleri karşısında "düşmanın, tehlikeli bir madde olarak ele alınması" olduğunu belirtmektedir (2013: 39). Savaş alanı ve düşman, tek taraflı olarak "güvenli alana" dönüştürülerek arındırılmaktadır. Tüm mekan, "güvenli alan" ve "düşman alan" olarak bölünmektedir (Chamayou, 2013: 37). Chamayou, bunu asimetrik savaşın radikalleşmesi olarak okumaktadır.

Yazar, kitabını bir dron pilotunun notlarıyla açmaktadır (Chamayou, 2013: 9): Dron, uzaktan kumanda edilmekte olan PlayStation türevi sanal ama aynı zamanda gerçek bir yırtıcıdır. Dron pilotu, artık sahada değildir. Mekanında düşmanı yoktur. Bir PlayStation deneyimi yaşar gibi gerçeklikle ilişki kursa da, makinesi ölüm saçmaktadır. Chamayou'ya göre, Clausewitz'in klasik tanımından farklı olarak, dron, savaşın düello fikrini içermemektedir (2013: 52). Mevcut şema avcı ve kurbanı arasındaki ilişkidir. Düşman, ne tanınmaya sahiptir ne de meydan okuma hakkına. Dron yakalar, vurur; yemi ise kaçar, saklanır. Böylelikle, düşmanlık saklambaç oyununa dönüşmektedir (Chamayou, 2013: 52-53). Askeri strateji, "önleyici" bir insan avı olarak işlemektedir. Savaşın önlenmesi

dokuma aletleri ve lir bugün kendi kendine işlemektedir ancak dokumacı ve lir çalan kişi mesleklerine "zincirlenmiştirler" (Koyré, 1981: 308). 
çabası, savaşın fiilen dönüşmesidir. Bu dönüşümün Clausewitz'in (2014: 113) "bukalemun" metaforuyla kast ettiği biçimselliğin ötesinde olduğu kabul edilebilir.

Dronun amacı bellidir. Her şey şeffaf olmalı ve dron her yerde olmalıdır. Dron böylelikle gözetleyecek ve gerektiğinde imha edebilecektir. İmha edilen düşman değil, W. Benjamin'in deyimiyle "sarfiyat malzemesine" dönüşmüş insandır (Kardeş, 2017: 43) . Düşman, burada artık daha çok paraziti ya da mikrobu anlatmaktadır. Chamayou şunun altını çizmektedir: Dronun, her yerdeliği, her şeyi bilmesine; her şeyi bilmesi de her şeye gücünün yetebilmesine olanak tanımaktadır (2013: 57-58). Dron, "her şeyi görendir" (Fr. omni-voyant) (Chamayou, 2013: 43).

Dron, her şeyi görür, bilir ve yapar. Böylelikle verileri ve insanları kendi şemalarına göre kataloglar. Artık yaşamın kendisi sterilize edilecek (kısırlaştırılacak) bir nesnedir. Güvenilir şeyler alanıyla tekin olmayanlar arasında tüm parametreler kurgulanır. Yaşam, onun sportif etkinliğine vesile olan donuk malzemeler yığınıdır.

Dronların, “iş kazaları” saymakla bitmez. Av-düşman öldürülürken yaratılan kısmi bölgenin türdeşleştirilmesi ve tamamen imha edilmesi savaşa dair tüm tanımları rafa kaldırdığı gibi, savaşın hukuki statüsüne ve devletlerin sorumluluk alanlarına ilişkin de boşluklar yaratmaktadır. Peki dron en temelde ne işe yaramaktadır?

Chamayou'nun bu soruya iki eksenli yanıt verdiğini söylemek mümkündür. Özetle söylenecek olunursa birincisi "gerilla savaşına" karşı verilen yanıt olarak dron; ikincisi ise modern egemenlik paradigmasının devlete yüklediği sorumlulukları hafifletme çabası olarak dron. Bunları açalım. Araştırmacı, dronu gerilla savaşına verilen geç bir yanıt olarak değerlendirmektedir (Chamayou, 2013: 93). Asitmetrik, düzenli ordu aleyhine savaşın elverişsiz koşullarını, gerilla aleyhine çevirme çabasını güden dron, "düşmanı düşmanlığından yoksun bırakma” işini üstlenmektedir (Chamayou, 2013: 93). Dronlaştırılmış "insan avı", antiterör söyleminin başarısı yanılsamasını da üretmektedir. Oysa Chamayou (2013: 108) bunun sonuçlarına dikkati çekmektedir: "Kazanılmayan savaşları sürdüren dokunulmaz bir iktidarın paradoksu şudur: Sürekli savaşlara doğru yol almak".

İkinci nokta ise modern devletin "protego ergo obligo"su ile ilgili husustur. Modern egemenlik teorisi, bireyin devlete tabi olması sonucu yurttaşa dönüşmesinin diyalektiğini anlatmaktadır. Devlet koruyacaktır ancak, yurttaş rıza göstermelidir. Devlet güvenliği tesis edecektir ancak, yurttaş onun yetkisini kabul etmelidir. Yurttaş haklarına kavuşmuştur, çünkü devletin varlığını onaylamaktadır. Bu ilişki içerisinde modernite, tüm liberal söylemlerinin ötesinde yurttaşın tüm haklar alanını aşan bir "feda" etme pratiği potansiyel olarak vardır. "Burjuvanın" tüm rahatı, devletin ona sunduğu koşullara yaslandığından, devlet olağandışı durumlarda onun rahatını askıya alabilmektedir. Dron, Cha-

\section{$102 \mid$ ETKileşim | Yıl1|Sayı2| Ekim 2018}


mayou'nun gözünde, liberal devletin, liberal ideolojisine uygun şekilde "feda etme"den (sacrifice) vazgeçişi anlatmaktadır. Dron, liberal devletin ideolojisiyle çelişmeden ürettiği savaşın adıdır. Savaş yapılır, ama fedakarlık yapılmadan (Chamayou, 2013: 248).

Peki bu, olumsuzlanması gereken bir pratik midir? Kayıpsız ve fedakarlıksız savaş üretmeyi niçin olumlamayalım? Kayıp olmaksızın kazanmanın, kendisi riske girmeden devirmenin, düşmanla yüz yüze gelmeden onu patlatmanın ideal savaş stratejisi olduğu söylenemez mi? Bu soruların etik, hukuki ve politik düzlemlerde yanıtları vardır.

\section{Sonuç}

Ne kadar çelişik gelirse gelsin, devletlerin arasındaki savaş çoğu kez hukuki bir durumu anlatmaktadır. Ölmeye gelen düşman, öldürmektedir ya da yola çıkmadan önce kendisini zaten feda etmiş savaşçılar vurmaktadır ve de vurulmaktadır. Robot vurduğunda bunun jus in bello'ya tabi bir savaş fiili mi olduğu yoksa cezai bir fiil mi olduğu sorusu gündeme gelmektedir. Dronun, işleyeceği bir savaş suçu, faili açısından belirsizdir. Sonuçta fiil dron tarafından icra edilmektedir, ancak sorumluluğun pilotta mı, generalde mi; yoksa ülkenin başkanında mı olduğu muammadır. Dron "sorumsuzluk fabrikası"nın tipik bir dispozitifidir (Chamayou, 2013: 239).

Dron vs. kamikaze: Aynı sorunun iki farklı seçeneğidir (Chamayou, 2013: 125). Bu seçenekler birbirlerini insanlıktan men eden insanlığın pratikleridir. Askeri ethos açısından, savaşçıya yüklenilmiş erdemleri aramanın sonuna geldiğimizi (gelindiğini) kabul edebiliriz: Post-heroik bir çağın içerisindeyiz. Artık zoraki yaratılmış askerlik destanlarının fiilen gerçekleşmediği bir çağ yaşanmaktadır. Her ne kadar televizyon haberleri, devlet adamları, filmler kahramanlık söylemleri üretseler de, bu söylemler çağın olmayan kahramanlığını inşa etmeye yetmemektedir. Artık "asker" ile "savaşçı" arasındaki uçurum bile derin yarıklarına kavuşmuştur. "Silah çıktı, mertlik bozuldu" çağından "mesafe ve hız arttı, savaşçı kayboldu" çağına ulaşılmıştır.

Dron, savaşçıyı figür olarak kaldırarak (Alm. Aufhebung), askeri "görülmeden gören" göze dönüştürmeyi başarmıştır. Bu askerin öldürmesi, artık savaşçının ölmeye hazırken öldürmesinden farklıdır. Savaşçı, düşmanıyla ve onun ölümüyle ilişkisini duyumsayabilecek durumdadır. Oysa dron çağının askeri açısından ölüm "bölümlerine ayrılmıştır" (Fr. compartimenter) (Chamayou, 2013: 176). Eichmann ${ }^{3}$ kadar masumdur/suçludur! "Sadece $x, y, z$ fiillerini gerçekleş-

\footnotetext{
${ }^{3}$ Adolf Eichmann (1906-1962): Üst düzey Nazi Subayı. "Nihai Çözüm" projesinde çalışarak binlerce Yahudi'nin katledilmesinde etkin rol aldı. Daha sonrasında, kaçıı̆̆ı Arjantin'den yakalanarak getirildiği İsrail'de, 1960-62 yılları arasında yargılandı. Bu yargılamalar esnasında sadece "görevi"ni yaptığını belirtti. Eichmann mahkemesini izleyen H. Arendt, "kötülüğün sıradanlığı" (banality of evil) kavramını Eichmann vakasını düşünürken üretti (Arendt, 1964: 119).
} 
tirmiştir" ama bu fiilin, imha edilmek istenen "hedefle" ilişkisi kısmileştirilmiştir. Dron, asker yaşantısının, savaşı bir kenara bırakıp savaşabilme kapasitesini anlatmaktadır. Böylelikle savaşçı ethos'undan, askerin nekroetiğine bir geçiş mümkün olmaktadır.

Haklı/adil savaş kavramının moda olmasına şaşırmamak gerekmektedir, zira bu politik mantık temel bir yola çıkış noktasını kabul etmiştir: Benim askerim öldürebilir ama seninkinin benimle savaşmaya hakkı yoktur. Ya da ben sana "sıfır kayıplı", "risksiz" savaşlar açabilirim, yani ben "jus ad bellum"a sahibim ve savaşta kendi adıma "jus in bello"yu işletirim ancak senin savaşma hakkın olmadığı gibi, benim sana savaşta yaptıklarımı senin bana yapma hakkının olması kabul edilemez. Dron, düşmanı düşmanlığından men etmeyi anlattığı kadar, bir politik topluluğun da kendi kimliğini insanlık fikri etrafında yalıtma ve sterilize etme çabasını imlemektedir.

Uluslararası hukukun üstünde bir süreç olarak dronize bir yerkürenin temel sorunu, gerçekten barışı tesis etmenin çok uzağında olmasıdır. Uzaktan savaş, şiddet hiperbolünü, azaltacak bir politik zihniyetin gelişmesine katkı sunmamakta, aksine savaşı insandan makineye havale ederek şiddetin yeni ve öngörülemez biçimlerini örgütlemektedir. Risksiz savaşın faturası, politik ilişkilerin dilini güç eksenine kaydırmak olacaktır. Dron, dünya politikasının, politik kısırlığının adıdır. Son olarak Cengiz Çakmak'ın sözleriyle bitirmek istiyorum: "Dron, bal yapmayan erkek arı, asalak anlamlarına gelir. Post-human çağı da eşek arısı çağıdır" (Çakmak, 2017). Dron, insana ve politikaya dair krizlerin kanıksandığı çağın semptomunu anlatmaktadır.

\section{Kaynakça}

Agamben, G. (2015). Stasis. (J. Gayrau, çev.). Paris: Editions Points.

Alliez, É. ve Lazzarato, M. (2016). Guerres et Capital. Paris: Éditions Amsterdam.

Arendt, H. (1964). Eichmann in Jerusalem. A Report on The Banality of Evil. New York: The Viking Press.

Aron, R. (2004). Paix et guerre entre les nations. Paris: Éditions Calmann-Lévy.

(2009). Penser la guerre, Clausewitz, 1. L'âge européen, 2. L'âge planétaire. Paris: Éditions Gallimard.

Benjamin, W. (1999) "Zur Kritik der Gewalt". von R. Tiedemann ve H. Schweppenhäuser (ed.) Walter Benjamin Gesammelte Schriften. (vol. II.). Frankfurt: Suhrkamp.

(2000). Euvres I. (M. de Gandillac, R. Rochlitz ve P. Rusch, çev.). Paris: Éditions Gallimard.

(2000) Cuvres II. (M. de Gandillac, R. Rochlitz ve P. Rusch, çev.). Paris: Éditions Gallimard.

Chaliand, G. (2009). Une histoire mondiale de la guerre. Paris: Éditions Odile Jacob.

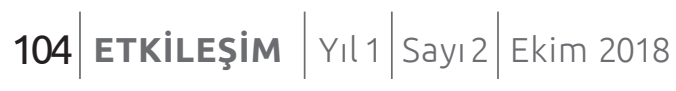


Chamayou, G. (2010). Les chasses à l'homme. Paris: Éditions La Fabrique. (2013). Théorie du drone. Paris: Éditions La Fabrique.

Clastres, P. (2016). Archéologie de la violence. La guerre dans les sociétés primitives. La Tour-d'Aigues: L'Aube.

Creveld, V. M. (1991). The Transformation of War. New York: The Free Press.

Çakmak, C. (12 Haziran 2017). https://twitter.com/cengizckmk/status/874244747 719843840 [ileti]. 1 Temmuz 2017.

Gros, F. (2006). États de Violence, Essai sur la fin de la guerre. Paris: Éditions Gallimard.

Kaldor, M. (1999). New and Old Wars, Organized Violence in a Global Era. Stanford, California: Stanford University Press.

Kant, I. (1999). Practical Philosophy. (M. J. Gregor, çev. haz.). Cambridge: Cambridge University Press.

Kardeş, M. E. (2015). Schmitt'le Birlikte Schmitt'e Karşı, Politik Felsefe Açııından Carl Schmitt ve Düşüncesi. İstanbul: Iletişim Yayınları. (2016). “Hegel ve Çağında Savaşın Anlamı”. Felsefi Düşün. 6. 11-113. (haz.) (2017). Dar Kapıdaki Mesih, Walter Benjamin'in Politik Felsefesi. istanbul: ithaki Yayınları.

Koyré, A. (1981). "Les Philosophes et la machine". Études d'histoire de la pensée philosophique. (305-339). Paris: Éditions Gallimard.

Münkler, H. (2010). Yeni Savaşlar. (Z. A. Yılmazer, çev.). ìstanbul: iletişim Yayınları. (2007). Empires, The Logic of World Domination from Ancient Rome to the United States. Cambridge: Polity Press.

Rousseau, J. J. (1964) CEuvres complètes 3: du contrat social, Ecrits politiques. B. Gagnebin ve M. Raymond (ed.) Bibliothèque de la Pléiade. Paris: Éditions Gallimard.

(1996). Euvres complètes 1, Les confessions; Autres textes autobiographique. B. Gagnebin ve M. Raymond (ed.) Bibliothèque de la Pléiade. Paris: Éditions Gallimard.

(2008) Principes du droit de la guerre, Écrits sur la paix perpétuelle. B. Bachofen ve C. Spector (ed) B. Bernardi ve G. Silvestrini (haz). Paris: Vrin.

Schmitt, C. (1932). Der Begriff des Politischen. Berlin: Dunker \& Humblot. (1992). La Notion de Politique-Théorie du Partisan. (M.-L. Steinhauser, çev.). Paris: Flammarion.

(2006). Theorie des Partisanen. Zwischenbemerkung zum Begriff des Politischen. Berlin: Dunker \& Humblot.

(2007). La guerre civile mondiale, Essais (1943-1978). C. Jouin (çev.). Paris: Éditions Ėre. 
von Clausewitz, C. (1935). Vom Kriege: Hinterlassenes Werk. A.W. Bode. Leipzig: Als Volksausgabe.

(2014). De la Guerre. (B. Chantres, çev.). Paris: Éditions Flammarion.

Waltz, N. K. (2001). Man, The State and War, A Theoretical Analysis. New York: Columbia University Press.

106 | ETKileşim | Yıl1|Sayı2|Ekim 2018 
